\title{
Feasible Analysis of Physical Education School of Baicheng Normal University Serving the Development of Social Sports in Baicheng Urban Area*
}

\author{
Zhancai Chu \\ Baicheng Normal University \\ Baicheng, China 137000
}

\begin{abstract}
Physical education department in local colleges serving local community sports can not only promote the development of community sports, meet the various fitness demands of people of different ages and enrich spare-time cultural life, but also provide an important practical platform for talent training and self-development of physical education departments and better realize themselves value. To this end, local sports colleges should carry out talent training break the traditional teaching mode, define training programs, and create outstanding features according to the demand for talents, social needs, and national fitness services of local sports development. This paper analyses the present situation of running school and existing problems of the physical education school of Baicheng Normal University by using literature review method, interviewing method and questionnaire method. According to the current needs of social sports in Baicheng City, this paper explores the feasibility of serving community sports by local colleges, and puts forward practicable and concrete paths.
\end{abstract}

Keywords-Baicheng Normal University; social sports; feasibility

\section{RESEARCH OBJECTS AND METHODS}

\section{A. Research Object}

School of Physical Education of Baicheng Normal University; Baicheng urban community; sports association (basketball association, football association) and enterprise and public institutions.

\section{B. Research Methods}

Literature review method, questionnaire method and interviewing method.

*Project: This paper is the phased research achievement of the 12th Five-Year Plan of Jilin Province's Educational Science "Research on the Physical Education Department of Local Colleges in Jilin Province Serving the Local Social Sports - Taking Baicheng Normal University as an example" (Project Approval No. GH150484).

\section{RESEARCH STATUS AND ANALYSIS}

A. Current Situation of Talents Training in Local Colleges and Regional Sports Development

At the present stage, although the information network is advanced, the communication between the training program of normal colleges and the development of regional sports undertakings and employers is not smooth, thus resulting in the disconnection between training and demand. In the work of sports talents training, the three parties should jointly establish a feedback mechanism of talent demand, simultaneously establish an online communication service system, make full use of the network and survey and visit to obtain the first-hand demand information of employers, and adjust the training strategy in time. At present, the demand of society for physical education talents in colleges is increasing year by year, but most of them are misplaced employment for students' diversification, and there are a series of contradictions and difficulties in running schools. The fundamental reason is that the physical education major in colleges has long been aiming at cultivating single orientated physical education normal students. Although it has cultivated a large number of physical education teachers for primary and secondary schools, which has contributed to the reform and development of basic education. However, with the change of society's view on talents and the accelerated process of sports socialization, daily life-based and industrialization, the disadvantages of the inherent directional talent training mode are increasingly exposed: the curriculum is relatively narrow, the degree of discipline is relatively low, the basic knowledge of students is not sufficient enough, the practical ability is not strong enough, the lack of innovative spirit, the ability to adapt to other work is poor, the professional orientation is too early, the source of students and career outlet are greatly limited, the training channels are single and closed, and it is not easy to adapt to the demands of modern society and the development of science and technology for various types and adaptive ability body teachers, etc. Therefore, the traditional "professional talent training mode" cannot solve the problems faced in the process of deepening the reform of physical education major 
today. Modern physical education in colleges must be reformed from the following aspects: diversification of training goals and training modes, optimization of curriculum structure, and improvement of practical teaching system, which enables the training of professional talents to continuously adopt the requirements of social development.

\section{B. Comparing the Information Provided by Baicheng Sports Bureau in 2015 and 2018} 2015:

Information provided by Baicheng Sports Bureau since

1) Sports organizations and facilities: There are 576 sports organizations of all kinds, 14 national-class youth sports clubs and 12 traditional sports schools in the city. The city's social sports instructors at all or different levels reached 1475, accounting for $0.73 \%$ of the city's total population, and volunteer training and volunteer service activities for national fitness became normal. The city and its five counties (cities and districts) have completed 20 "One of Five" projects, of which the State Sports Administration has funded three "Snow-Charcoal Project" in our city. In 106 communities of the city, 82 fitness paths have been constructed, with coverage rate reaching $77 \%$; 343 fitness equipment have been constructed in 918 administrative villages, with coverage rate reaching 37\%; 4 national fitness centers, 34 township fitness squares, 2 sports parks, 18 urban fitness squares and 9 fitness trails have been established.

2) Sports activities: The national fitness activities in the city, such as ice and snow activities, "small marathon" contests, swimming competitions, staff table tennis competitions, youth table tennis competitions, basketball competitions, badminton competitions, elderly gate ball competitions, square dance competitions, run through the whole year. Actively create a "one place, one feature" featured brand of national fitness activities. Nadam Fair with Baicheng characteristics has been expanded from municipal level to county level and even to ethnic autonomous townships, which has effectively promoted the development of traditional ethnic sports and become the flagship brand of Baicheng. According to incomplete statistics, the city holds more than 130 national fitness activities and competitions of all kinds every year, with more than 400,000 participants.

3) At present, the structure of teams of social sports instructors and national fitness volunteers is not perfect, with the number distribution being not uniform enough: There are more teams in towns, less in rural areas, more teams composed by elderly people and less by young people. How to increase the proportion of young people in the team of social sports instructors, especially in rural areas, is a problem we are facing.

4) Undertakes various competitions in 2018: Mass Competition Weiqi Project of the 13th National Games, Shadowboxing Qualification Trials of the 13th National Games in Baicheng Competition Area, First Gate Ball
Invitation Competition in Baicheng in Jilin province, Baicheng in Jilin province Competition Area Five-person Social Group Competition of China Football Folk Championship "I Love Football", the whole city's Small Marathon Competition and Primary and Secondary School Students "Three Cup Competition" in Tongyu County, Baicheng Competition Area Semi-Final of 2017 Jilin Province Mass Basketball League of Baicheng "Sports Lottery Cup", "Sports Lottery Grand Lottery Cup", Baicheng Seventh Youth Table Tennis Competition, "China Telecom Tianyi Optical Fiber and Broadband" Cup Square Dance Exhibition Activity, Baicheng Fourth "Zhongyou Cup" Staff Officers Table Tennis Competition. The above events are mostly sponsored by the Physical Education School of Baicheng Normal University and held in the gymnasium.

\section{Feasible Analysis of Colleges SeRVing Social SPORTS DEVELOPMENT IN BAICHENG URBAN AREA}

As a local university, Baicheng Normal University not only focuses on training comprehensive and applied talents to adapt to social development, but also actively assumes the responsibility of serving the society. The abundant service resources that are boasted by the school lay a good foundation for serving the society.

\section{A. Talent Resources Advantages}

Baicheng Normal University is the only undergraduate university in western Jilin province. Physical education school now has two undergraduate majors, including physical education, social sports guidance and management, which has trained a large number of sports professionals with excellent professional foundation, and has delivered physical education teachers and social sports personnel for the whole country. Physical education school has 36 highly accomplished professional teachers and 5 teaching auxiliary personnel who are graduated from 12 universities in China. Among them, there are 5 professors, 15 associate professors, 14 lecturers, 1 doctoral degree teacher and 25 master degree teachers, accounting for $70 \%$ of the total teachers. More than 20 teachers successively have gone to schools with high level of teaching and scientific research to further their studies. Physical education school has gradually established the training goals of sports major that are suitable for the development of our institute based on the basic education in the west of Jilin province and facing the future and serving the demands for sports talents at different levels of society.

Through the construction that pays more attention to teacher troop, the teaching quality in physical education school has been steadily improved, and good teaching results have been achieved. One course has been rated as provincial high-quality courses, two as provincial excellent courses, and 10 as excellent courses in the college successively. In recent years, our teachers have won two provincial and ministeriallevel awards, one Zeng Xianzi teaching award, one advanced individual of "three educators" in provincial colleges, seven prizes in the basic skills competition of teachers in Jilin province, five teachers have been rated as school teaching tutors, subject leaders and academic leaders. Meanwhile, many teachers have won the titles of outstanding teachers, 
backbone teachers and novice teachers in the teaching competition held by university. Teachers have presided over more than 10 topics at or above the provincial level, edited or participated in compiling more than 10 textbooks, and published more than 100 papers in core journals. These theoretical research results have created favorable conditions for promoting the development of community sports and guiding residents in exercise scientifically.

\section{B. Site Facility Conditions}

The physical education school has four laboratories, a multi-functional gymnasium of more than 9600 square meters, outdoor track and field venues, volleyball venues, basketball venues, tennis venues, etc. These venues have all complete facilities and elegant learning environment. Apart from the daily use of teaching and training, part of the venues and equipment are vacant in the spare time. If the opening to the outside world is made full use, it will create better conditions for community residents' physical fitness.

\section{Social Development and Self-development Needs}

As a place of strategic importance in the west, the construction of Baicheng city must not lack sports culture. Under the demand of the future development of urban culture, the construction of sports culture will become an important part of the cultural construction of Baicheng city. As an important place for the dissemination of advanced knowledge and culture, local colleges are closely linked with the development of local culture. Therefore, own advantages should actively be used to serve local development and effectively promote the construction of local culture. In the report of the Nineteenth National Congress, General Secretary Xi Jinping points out that it proposes to "develop national fitness and competitive sports in an all-round way", carry out extensive national fitness activities and speed up the construction of a sports country, which national fitness has become a national strategy. Meanwhile, it has become a consensus on sports is people's livelihood. In the training of talents, colleges should pay attention to the training of applied talents adapted to social development, actively participate in social practice, increase students' chances of contacting society in practice in order to cultivate students' social responsibility, strengthen their practical ability and improve their comprehensive quality in community sports service.

\section{Suggestions on Local Colleges Service COMMUNITY SPORTS}

Local colleges service social sports is the ultimate goal of the national fitness for all strategy, which not only conforms to China's national conditions, but also meets the national fitness service system. How to improve the current community sports service system in China, solve the problems existing in the service system, and realize the winwin results of university services society and selfdevelopment, the key is to find the entry point of serving community sports and the fit point with the current service system.

\section{A. Active Participation in Community Sports Service Practice}

Colleges participate in community sports services, which can not only establish a good social image, but also conducive to the professional construction of sports departments, cultivate students' comprehensive quality and practical ability, and improve the quality of personnel training. Therefore, we should attach great importance to it and actively participate in it.

\section{B. Providing Necessary Working Conditions}

In order to ensure the normal proceeding of community sports service, it is necessary for the community to provide certain transportation and living and other basic subsidies for students and teachers in the process of serving community residents for exercise, which not only can improve the enthusiasm of students, but also is conducive to the longterm development of activities. At the same time, in order to ensure the long-term development of the model, it needs to purchase accident insurance for teachers and students and provide them with the necessary security assurance.

\section{Establishing a Good Cooperative Mechanism}

Physical education department in colleges should take the initiative to contact with the relevant departments of the community, establish cooperative relations, encourage teachers and students to use their professional expertise in order to promote the development of various forms of community sports service activities, enrich the practical effects of teachers and students, improve the enthusiasm of teachers and students in serving community sports and guarantee the smooth proceeding of services in the long run, thus gradually developing towards the direction of normalization.

\section{Changing the Traditional View of Teaching}

It is urgent to cultivate students' lifelong sports consciousness and exercise habits, master scientific exercise methods, and enhance their sense of serving local areas. In order to change the traditional teaching views and realize the transformation from sports technique education to scientific fitness education, the teaching contents, assessment contents and methods should be adjusted according to the laws of fitness and physical and mental development of college students. Optional courses of local characteristic sporting events can be offered to stimulate students' interest in taking part in physical exercise and create conditions for the inheritance of folk sporting events. For example, the winter sporting events with Baicheng features are skating and skiing. Baicheng can be able to undertake provincial competitions and hold national ice activities. In this activity, the cultivation of students' interest should be strengthened, and the cultivation of students' project skills should be paid attention to, which makes students can master the sports ability. Secondly, the teaching content with a sense of the times should be increased, such as aerobics, Latin dance bodybuilding exercise, taekwondo, bodybuilding, etc. At present, square dance is popular, which are mostly the combination of bodybuilding exercise and dance. All these 
cultivate students' comprehensive abilities such as rhythm, aesthetics and rhythm, and train guiding talents for social sports.

\section{CONCLUSION}

The development of sports in local colleges should combine with the actual needs of society, change traditional concepts, and get rid of the misunderstanding of personnel training. It not only trains teacher-type talents, but also serves the development of social sports cause. To take the social sports undertaking development service as the orientation and the goal, realize the combination of college sports and local sports and realize the integration of regional sports and sports resources complement each other, which makes the best use of things and people as well as the mutual promotion and common development.

\section{REFERENCES}

[1] Cao Dongfang. Reflections on Physical Education Curriculum Reform in Local Universities [J]. Journal of Shanxi Datong University (Natural Science Edition) 2008, 24 (4): 27-28. (in Chinese)

[2] Ruan Chang. Research on the Professionals Training of Chinese Language and Literature Major in Local Universities [J] Heilongjiang Higher Education Research, 2009, (11): 146-148. (in Chinese)

[3] Peng Changjin. Difficulties and Countermeasures of Higher Physical Education [J]. Journal of Xiangtan Normal University (Social Science Edition), 2009, 31 (2): 191-193. (in Chinese)

[4] Wang Daojie, Cheng Zaikuan. Evolution of the Characteristics of Multi-abilities Training in the One Major of Physical Education of Beijing Sports University [J]. Sports Culture Guide, 2010, (12): 66-67, 81. (in Chinese)

[5] Su Yihua. Discussions on the Proportion of Subjects to Technical Subjects in the Curriculum of Physical Education Major[J]. Journal of Wuhan Institute of Physical Education, 2006, (2): 85-88. (in Chinese)

[6] Gu Yuanyan. Physical Education Teachers and Community Sports Construction [J]. Journal of Physical Education, 2001. (in Chinese)

[7] Wang Fei, Geng Tingqin, Chen Yongfang. Reflections on the Training Objectives of Undergraduate Physical Education Major in China [J]. Journal of Shandong Institute of Physical Education, 2009, (12): 83-85. (in Chinese)

[8] Zhang Yiliang. "Combination of Sports and Education" - Exploring the Training of Sports Talents in Primary and Secondary Schools [J]. China School Sports, 2011, 3 (1): 66. (in Chinese) 